\title{
A INTERDISCIPLINARIDADE DO DIREITO AMBIENTAL NO PONTAL DO PARANAPANEMA: PRESIDENTE VENCESLAU-SP
}

Lucas Cesar Bonato Rós; Maria Helena Pereira Mirante; Fabio Ferreira Morong.

Universidade do Oeste Paulista-UNOESTE, Presidente Prudente, SP. E-mail: lucas.b_ros@hotmail.com; madelainy1361@hotmail.com; fabiomorong@hotmail.com

\begin{abstract}
RESUMO
A temática sobre a interdisciplinaridade do Direito Ambiental no Pontal do Paranapanema: Presidente Venceslau-SP, em que tornou a centralização do capital nas porções de raros e de poucas pessoas, acarretando resultados cruéis na sociedade moderna. Esses resultados abordaram e apreendem a história social, provocando supressões, dessemelhança social e inferioridade econômica, a uma ampla quantia da população. O debate sobre a relevância do planejamento ambiental no munícipe, é um tema seriamente intenso, ao mesmo tempo, carecido ao permanecer confrontando com um amplo impacto ambiental, que estende não simplesmente a região, mas sobretudo seus cidadãos. Nesse contexto, em que o planejamento ambiental é essencial, para que uma cidade se desenvolva adequadamente, de modo que sua economia e progresso, caminhem juntos, com a preocupação com o meio ambiente.

Palavras-chave: Interdisciplinaridade, Direito Ambiental, Pontal do Paranapanema, Presidente Venceslau-SP
\end{abstract}

\section{TITLE: THE INTERDISCIPLINARITY OF ENVIRONMENTAL LAW IN THE COUNTRY OF PARANAPANEMA: PRESIDENT VENCESLAU-SP}

\footnotetext{
ABSTRACT

The thematic about the interdisciplinarity of Environmental Law in Pontal do Paranapanema: President Venceslau-SP. It has made the centralization of capital into the rare and few people, leading to cruel results in modern society. These results approached and apprehend social history, causing suppression, social dissimulation and economic inferiority, to a large amount of the population. The debate on the importance of environmental planning in the city is a serious issue, while lacking in environmental impact, which extends not only to the region but also to its citizens. In this context, where environmental planning is essential, for a city to develop properly, so that its economy and progress, walk together, with concern for the environment.

Keywords: Interdisciplinarity, Environmental Law, Pontal do Paranapanema, President VenceslauSP
} 


\section{INTRODUÇÃO}

Esse trabalho sobre a interdisciplinaridade do Direito Ambiental no Pontal do Paranapanema: Presidente Venceslau-SP, tem como foco principal em uma leitura atualizada e um olhar geográfico da realidade, em que o município de Presidente Venceslau-SP, está dentro da área no Pontal do Paranapanema, incumbindo à localidade administrativa de Presidente Prudente.

Nesse contexto, juridicamente a Constituição Federal de 1988 tem como princípio constitucional, o cumprimento da função social da propriedade do qual podemos destacar o seguinte: $O$ princípio da função social da terra, significa que devemos produzir, gerar empregos, criar vida e, em meras palavras, seria o dever social. No qual, deva corresponder necessariamente um direito de uso do solo, sendo que o pleno cumprimento dessa lei, ainda depende da vontade política do Estado, ou melhor, de projetos do governo. (SPAROVEK, 2003)

Com informações relevantes, que nos possibilita à afirmar com convicção que a implantação dos assentamentos rurais, tem contribuído para o desenvolvimento socioeconômica, político e ambiental da região do Pontal de Paranapanema.

A região no Pontal do Paranapanema, várias florestas foram extintas e abrigaram importantes tumultos no emprego do ambiente territorial. Procedendo, caso fortuito relevante, carecendo de recursos apropriados, ao modo sustentável do solo e dos diferentes recursos naturais.

Um dos principais pontos importantes, para preservação do meio ambiente, de acordo com o ITESP:

Promover a educação ambiental; recuperar e controlar voçorocas; recompor e enriquecer as Áreas de Preservação Permanente (APP) e as Reservas Florestais Legais (RFL); introduzir técnicas conservacionistas na exploração agrícola dos lotes; evitar a poluição do solo e da água; e, promover fontes de rendimento econômico aos assentados (ITESP, 1998, p.23).

Outra fonte importante a ser pautado, estaria relacionado ao desenvolvimento rural sustentável, que surgiu da crescente percepção acerca dos impactos ambientais e da agricultura convencional, com destaques práticos em corrigir e segmentar, a partir da década de 1970. (FERNANDES, 2000)

Assim, o tema agrário retrata um ambiente fundamental no capitalismo, ao caminhar, às dificuldades não são integralmente esclarecidos, mas reduzido com o incremento e caracterização de políticas públicas, de modo socioeconômico. Sejam, com as famílias dos assentados de Presidente Venceslau-SP, ou com todas as famílias assentadas no Pontal do Paranapanema.

\section{METODOLOGIA}

Para cumprir o objetivo proposto, o presente trabalho tem um reforço à discussão sobre a interdisciplinaridade do Direito Ambiental no Pontal do Paranapanema: Presidente Venceslau-SP, o trabalho seguiu os métodos dialético-dedutivo, com emprego de pesquisa à legislação, autores e jurisprudência acerca da matéria como forma de objeto do estudo, no acréscimo do conteúdo, a propósito, dos contornos dos conhecimentos da ciência, sobre o embasamento nas relações humanas e físicas, de modo explícito, claro, inteligível e funcional.

\section{DISCUSSÃO}

O município de Presidente Venceslau-SP, decorreu-se, com a extensão dos trilhos da Estrada de Ferro, da Alta Sorocabana, para região. O município se amparou com base em uma economia extrativista, sendo sua evolução econômica caracterizada em três fases: a) café, até meados da década de 1930; b) algodão e amendoim, até meados da década de 1950 e a fase da pecuária de corte, a partir de meados da década de 1950. (LEITE,1985) 
Importante observarmos que, a terceira fase foi marcada pela evasão de trabalhadores do campo para a cidade (êxodo rural), fator importante que intensificou o processo de urbanização do município de Presidente Venceslau.

Em consequência desse procedimento de urbanização acelerado, trouxe implicações para o munícipe de Presidente Venceslau, a começar de sua metodologia de colonização, que experimentou com os interesses e controle dos ilustres, amplos proprietários de terras. Além de improvisarem seus progressos, que aconteceu de feitio irresponsável, incidindo por cima do ecossistema originário. (CAMARA; RODRIGUES; FELÍCIO, 2016)

Desenvolvendo assim, uma administração desacertado e sem qualquer planejamento ambiental.

Segundo Franco (2001, p. 35).

Planejamento Ambiental é todo planejamento que parte do princípio da valorização e conservação das bases naturais de um dado território como base de autosustentação da vida e das interações que a mantém, ou seja das relações ecossistêmicas.

Infelizmente, na maioria dos municípios pertencentes ao Pontal do Paranapanema, não encontramos a aplicabilidade desses princípios no seu planejamento ambiental.

Para ficar claro esta questão, a atual Constituição Federal dentro do Capítulo III da Política Agrícola e Fundiária e da Reforma Agrária, em seu Art. 186 à função social é cumprida quando a propriedade rural atende, simultaneamente, segundo critérios e graus de exigência estabelecidos em lei, aos seguintes requisitos:

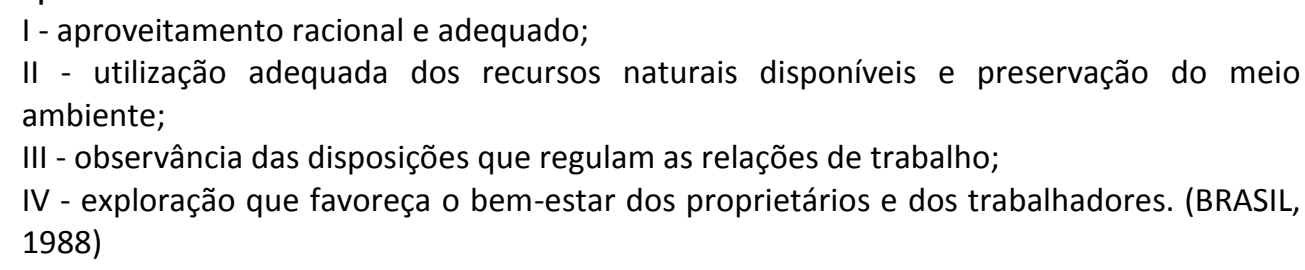

Nesse contexto, a reforma agrária, assim como qualquer política pública, é um resultado de conflitos e de interesses e precisa da existência de um governo que a coloque como tema privilegiado de ações.

Historicamente, através do processo de industrialização à partir da década de 50 e do golpe militar de 1964, para o final do século XX, deu-se a compreensão de que os pobres, que residiam nas cidades e nos campos são sujeitos sociais, com maneiras de estudo para compreensão da situação real de pobreza existente no mundo. (BOUÇAS, 2011)

Depois dessa compreensão, à reforma agrária é inserida nos terrenos das políticas públicas, necessários para redução da extrema concentração fundiária no Brasil, sendo contextualizado, respectivamente no Pontal do Paranapanema.

Desta maneira, podemos analisar que a reforma agrária, é a transformação da sustentação agrária de um nação, ou lugar, com paisagem a uma repartição mais justa de terras, como forma de faturamento agrícola, acarretando e impetrando à influência determinada do Estado.

Mesmo que as políticas aplicadas com a reforma agrária, não tenham obtido o sucesso almejado, há de se convir que com a sua aplicabilidade, foi possível desconcentrar a terra e promover uma serie de transformações no campo e na cidade, pelas observações e as condições em que as famílias chegaram ao assentamento e comparar com a situação atual, sendo fonte do fator principal a determinação do impacto socioterritorial. (FERNANDES, 2000)

A partir da proporção social, fator determinante para confirmação das políticas de implantação de assentamentos rurais, que jamais devem ser tomadas como políticas compensatórias, mas sim de políticas de desenvolvimento, a grande diferença está na conquista direitos que foram historicamente negados. 
Apesar de que, uma porção dos indivíduos específicos aos assentamentos não possuírem uma compreensão em relação a verdadeira administração de fundação, às aludidas políticas, sobrepostas aos assentamentos rurais. Geram a evolução regional à dimensão de que, ajustam o desenvolvimento de distintos esferas na economia. (THOMAZ JUNIOR, 2009)

Os impactos tanto no campo social, quanto no campo ambiental, podem ser observados a partir das transformações e processos existentes. Especialmente, dos esquecidos que ficaram abrangidos, da sua propriedade rural, que ficou modificado em assentamentos com múltiplos lotes, os domicílios que advieram a arranjar, às paisagens transformados. Sendo assim, surgiram as passagens, os colégios, espaços sociais, galpões, hospitais, entre tantos outros. (OLIVEIRA, 2007)

Com a ocupação dos solos pelas famílias, alguns impactos sociais que foram relevantes na metodologia e na evolução, considerando a sua compreensão no qual cabe descrever: à proporção social, econômica, ambiental e política.

Continuando, por conseguinte destas proporções, apoiamos em múltiplos identificadores que abordam necessariamente nos feitios, que evidenciam o desenvolvimento na condição de vida e no aumento das perspectivas de opções dos grupos assentados, em que faz sentido e perspicaz na aquisição da terra.

Com relação aos impactos ambientais, causados com a ocupação das famílias nos referidos assentamentos, tomamos como base as alterações nas paisagens locais e regionais, com início na inserção dos assentados, capacidade de preservação ambiental cometidos e a concepção de prevenção nas áreas de reserva. (SANTOS, 2012)

Ao estudarmos, o celebre de apropriação na região do Pontal, notamos o grande identificador de degradação ambiental, originários dos métodos desequilibrados de utilização e prático do solo; dos desflorestamentos; no emprego em determinadas extensões da região, para aniquilamento da mata desde o período inicial da colonização. (CAMARA; RODRIGUES; FELÍCIO, 2016)

Também, o afronta em extensões de proteção permanentes de nascentes e matas ciliares; o método incessante das queimadas e da monocultura. Por fim, encontra-se vivo as restrições dos recursos naturais memorizados nos assentamentos, que são necessitados especialmente, ao caso, dos próprios estarem inseridos em áreas já destruídos. (CARVALHO, 2004)

Há percepção, que os assentamentos rurais apesar de expandido o comparecimento humano, a respeito do ambiente natural, que encontra partida dentro da paisagem humanizada, abrangidos os modos das propriedades oriundos no solo, às famílias tem adaptado a recuperação das pastagens.

A restauração e recomposição de reservas florestais, importante meio de configuração morosa e restrita, contudo andando na acepção correta. Pensando nesse ponto, falta muito para ser avançado como meios permanentes na educação ambiental e também nos institutos adequados.

\section{CONCLUSÃO}

O direito ambiental, é uma das ferramentas que concretiza uma matéria interdisciplinar, que faz um entrelaçamento ou uma ligação direta com o direito e outros ramos. Nele, compreendemos que tem atuação na defesa de interesses difusos, a expressão o "bem de uso comum do povo" do atual artigo 225 da Constituição Federal.

Nesse contexto, os problemas ambientais afrontados nos pontos delimitados no pontal do Paranapanema, em que induziram paulatinamente a evolução do Direito Ambiental, que é o subramo do Direito e que tem como objetivo normatizar a relação do homem-natureza, de condição a assegurar o equilíbrio natural e a qualidade de vida, acima de tudo como forma sustentável a todos. 
Assimilar as analogias que se formam entre o homem-natureza e meio ambiente, é assunto filosófico, na tentativa de uma esclarecimento para distinção observada das pessoas. A ciência geográfica, desde a sua criação, tem afinidades comuns de seus fundamentais objetivos.

De fato, grandes debates que dificultam a relação homem-natureza, e os entendimentos jurídicos que tomam maior atenção, desde seu modo histórico e técnico, seria capaz acarretar diferente direção para os preceitos ambientais. Isto é, a produção, análise e utilização da norma ambiental, estaria evidenciado com a relação direta do direito ambiental e da geografia.

Conforme os pontos estudados nesse trabalho, compreendemos com atenção, a falta de preservação do meio ambiente, e a sustentabilidade de forma direta a geografia no pontal do Paranapanema, delimitados os problemas políticos, econômicos e socioambientais.

Assim, essas considerações realizadas, tem em contrapartida, que ser realizado uma forte e concreta educação ambiental, quanto mais debatidos, seja em campos, seja em cidades, informando ao cidadão sobre seus reais benefícios, trará consigo um futuro regrado de benefícios para toda a sociedade em diversos fatores do Direito Ambiental e a Geografia, delimitados no trabalho.

\section{REFERÊNCIAS}

BOUÇAS, K. F. Entrevista no processo de trabalho do assistente social: uma análise crítica da utilização deste instrumento na equipe de serviço social do CEMEAES - Macaé/RJ. Rio de Janeiro. 2011. 80p. Rio de Janeiro. Disponível em: <https://app.uff.br/riuff/bitstream/1/5240/1/TCC\%20KARINE\%20REBOU\%C3\%87AS.pdf>. Acesso em: 06 Abr. 2018.

BRASIL. Constituição (1988). Constituição da República Federativa do Brasil. Brasília: Senado Federal, 1988.

CAMARA, J. H. C; RODRIGUES, B. M; FELÍCIO, M. J. O justo e o legal a partir dos impactos ambientais no pontal do paranapanema: encontros e desencontros. Periódico eletrônico fórum ambiental da alta paulista, 2016.

CARVALHO, H. M. de. Política compensatória de assentamentos rurais como negação da reforma agrária. Revista NERA, Ano 07, n.5. Presidente Prudente, 2004, p. 113-122 Disponível em: <http://www2.fct.unesp.br/nera/revistas/05/10_horacio_carvalho.pdf>. Acesso em: 13 Mar. 2018.

FERNANDES, B. M. A formação do mst no brasil. Petrópolis: Vozes, 2000. Disponível em: <http://www.reformaagrariaemdados.org.br/sites/default/files/A\%20forma\%C3\%A7\%C3\%A30\%2 0do\%20MST\%20no\%20Brasil\%20-\%20Bernardo\%20Man\%C3\%A7ano\%20Fernandes.pdf>. Acesso em: 08 Fev. 2018.

FRANCO, M. de A. R. Planejamento ambiental: Para a cidade sustentável. 1. ed. São Paulo: Annablume: Edifurb, 2001. Disponível em: <https://www.livrebooks.com.br/livros/planejamentoambiental-para-a-cidade-sustentavel-maria-de-assuncao-ribeiro-franco-nxnlntlyciic/baixarebook>. Acesso em: 06 Abr. 2018.

ITESP - Fundação Instituto de Terras do Estado de São Paulo. São Paulo, Pontal Verde: Plano de recuperação ambiental nos assentamentos do pontal do paranapanema. №1 (Jul 1998). Sao Paulo: ITESP, 2eed., 2000, 80p: il., 23cm. - (Série cadernos ITESP/Secretaria da Justiça e da Defesa da

Cidadania).

Disponível em: 
<www.itesp.sp.gov.br/br/info/publicacoes/arquivos/pontal_verde_2e.pdf>. Acesso em: 09 Abr. 2018.

LEITE, J. F. A alta sorocabana e o espaço polarizado de Presidente Prudente. Faculdade de Filosofia, Ciências e Letras - FFCL. 1985.

OLIVEIRA, A. U. Modo de produção capitalista, agricultura e reforma agrária. São Paulo: FFLCH, 2007,10 ed, 184p. Disponível em: <http://www.gesp.fflch.usp.br/sites/gesp.fflch.usp.br/files/modo_capitalista.pdf>. Acesso em: 06 Abr. 2018.

SANTOS, J. D. dos. Desenvolvimento rural, biodiversidade e políticas públicas. Desafios e antagonismos no Pontal do Paranapanema-sp. Versão revisada de acordo com a resolução CoPGr 5890 de 2010. Piracicaba, 2012. 295p. : il. Tese (doutorado) escola superior de agricultura "Luiz de Queiroz".Piracicaba-SP. Disponível em: <https://www.teses.usp.br/teses/.../11/.../tde.../Joao_Dagoberto_dos_Santos_versao_revisada. pdf>. Acesso em: 17 Jan. 2018.

SPAROVEK, G. A qualidade dos assentamentos de reforma agrária. São Paulo: páginas e letras, 2003.

THOMAZ JUNIOR, A. Dinâmica geográfica do trabalho no século XXI - limites explicativos, autocrítica e desafios teóricos. Tese (livre-docência em geografia). Presidente Prudente, FCT/Unesp, 2009. 